\title{
Lieber jung, reich und gesund ...
}

\section{Anna Sax}

Lic. oec. publ., MHA, Mitglied der Redaktion

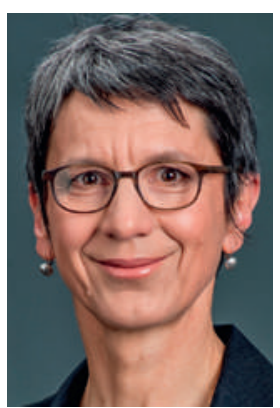

Kürzlich füllte ich wieder einmal auf einem InternetPortal den Fragebogen zur Lebenserwartung aus. Gefragt wurde unter anderem nach Erbfaktoren, Gesundheitsverhalten, Bildung, Einkommen und sozialen Kontakten. Und da durfte (oder musste) ich feststellen, dass meine statistische Lebenserwartung 98 Jahre beträgt. Also fast 100! Anschliessend ging ich nochmals auf das Portal und korrigierte drei Faktoren: Bildung, Einkommen und Zivilstand. Laut dem neu ausgefüllten Fragebogen habe ich nun die Grundschule abgeschlossen, verdiene weniger als 48000 Franken pro Jahr und ich bin geschieden. Und siehe da, schon sinkt meine statistisch wahrscheinlichste Lebenserwartung auf «nur» noch 89 Jahre. Werde ich zusätzlich zur Raucherin, füge ein paar Kilo Körpergewicht hinzu und trinke ein, zwei Gläser mehr pro Tag, zieht das Programm weitere Lebensjahre ab. Dieser Test ist fragwürdig, denn solche statistischen Werte sind zwar aus epidemiologischer und versicherungstechnischer Sicht von Bedeutung, können aber sicher nicht auf den Einzelfall angewendet werden. Interessant daran ist, dass er abbildet, was seit langem bekannt ist und auch der neueste Gesundheitsbericht wieder bestätigt: Wer reich und gebildet ist, ist auch gesundheitlich im Vorteil. Gut verdienende Akademikerinnen und Akademiker rauchen weniger, essen gesünder, bewegen sich mehr, haben weniger Übergewicht, sind sozial besser eingebettet, glücklicher und gesünder. Und sie werden älter.

\section{Der Einfluss der sozialen Lebenslage auf die Gesundheit ist weit grösser als derjenige der Medizin.}

Der Einfluss der sozialen Lebenslage auf die Gesundheit ist weit grösser als derjenige der Medizin. In soziale Sicherheit und Gesundheitskompetenz zu investieren ist daher aus volkswirtschaftlicher Sicht effizienter als immer mehr teure medizinische Technologien und Medikamente einzuführen. Das ist nicht neu und wird durch zahlreiche Berichte und Studien bestätigt, gerade wieder durch den erwähnten Gesundheits- bericht 2015, der sich mit der Entstehung und Bekämpfung von nichtübertragbaren Krankheiten beschäftigt. Das Wissen über die Bedeutung der sozialen Gesundheitsdeterminanten ist empirisch gestützt und in $\mathrm{Pu}$ blic-Health-Kreisen längst verwurzelt, doch politisch und im Gesundheitsmarkt spielt es kaum eine Rolle: Wer will schon in etwas investieren, was letztlich dazu beiträgt, die Einnahmen von Spitälern, Ärzteschaft und Gesundheitsindustrie zu verkleinern? Zwar entwickeln Bund und Kantone zur Zeit eine Strategie gegen nichtübertragbare Krankheiten, in deren Rahmen die Besserstellung wenig privilegierter Bevölkerungsschichten ebenfalls diskutiert wird. Doch sollen dadurch bitte keine Mehrkosten für die Steuerzahlenden entstehen.

\section{Die Herstellung von Chancengleichheit ist kein} Geschäftsmodell, und für das Vermitteln von Gesundheitskompetenz gibt es keinen Markt.

Leider ist es so, dass auch Gutsituierte nicht darum herumkommen zu altern und zu sterben. Die Angst vor dem bevorstehenden körperlichen und geistigen Verfall ist in der Babyboom-Generation, der auch ich angehöre, höchst präsent. Das eröffnet schöne Geschäftsperspektiven für alle, die Angebote für diese Zielgruppe im Portefeuille haben: Fitnessprogramme für Körper und Geist, Anti-Falten-Therapien, Wellnessangebote, Functional Food, Kultur und Bildung. In der Werbung sind zunehmend fitte "alte» Menschen $\mathrm{zu}$ sehen, wobei ich allerdings den starken Verdacht hege, dass es sich jeweils um jüngere Schauspielerinnen und Schauspieler mit grau eingefärbten Haaren handelt. Die Herstellung von Chancengleichheit ist dagegen kein Geschäftsmodell, und für das Vermitteln von Gesundheitskompetenz gibt es keinen Markt. Wirklich alte, gebrechliche Menschen dienen kaum als Rollenvorbild. Obwohl unsere Lebenserwartung steigt, wird es immer schwieriger, in Würde alt zu werden und zu sterben. Und so löst die Vorstellung, eventuell nochmals mehr als 40 Jahre auf dieser Welt zu leben, auch bei mir nicht ungeteilte Begeisterung aus. 